\title{
PERFORMANCE OF HUBBARD CLASSIC BROILER PARENTS AND FIT THE REGRESSION MODELS FOR THEIR PREDICTION
}

\author{
M. K. I. Khan and S. Ahmed
}

\begin{abstract}
The present study was conducted on Hubbard classic broiler parents in the Bangladesh Rural Advancement Committee (BRAC) poultry farm in Chittagong, Bangladesh to know the productive, reproductive performance and for modelling the performances for their prediction. The average live weight and egg production of Hubbard classic broiler parent were obtained as $3412.48 \pm 137.773 \mathrm{~g} / \mathrm{hen}$ and $170.99 \pm 1.012 \mathrm{eggs} / \mathrm{hen} / \mathrm{year}$, respectively. By using the parameters of linear regression and quadratic polynomial regression equation the yearly predicted egg production (number), live weight (g) and feed intake (g) were predicted. The $\mathrm{R}^{2}$ and CV fit statistics were used to compare the model performance and actual and predicted values. The actual and predicted value for live weight and feed intake was similar except yearly egg production (number).
\end{abstract}

Key words: Broiler parent, Performance, Modelling, Fit statistic, Predicted yield

\section{Introduction}

Broiler breeder production is one of the profitable production activities as like as commercial hybrid broiler and layer production in Bangladesh. Producing broiler breeder is also more remunerative than commercial broiler (Farooq et al., 2001; Asghar et al., 2000 and Farooq et al., 2003). The parent growers are interested to select strain well adapted to local condition, and inheritance capacity for producing quality hatching egg is given prime consideration (Hossain et al., 2005).

Commercial farmers use some exotic broiler breeds: Hybro-PN, Hubbard classic, Cobb-500, Hybro-PG and Ross (Saleque and Rozen, 2007). Productive and reproductive fitness of Hubbard classic is excellent in environment controlled house (Fattah, 2003) in Bangladesh. The Hubbard classic is a feather sexable fast growing broiler that attains 3.6 to $3.8 \mathrm{~kg}$ body weight at 64 weeks of age with annual hen housed egg production of 186 and $84 \%$ hatchability (Hubbard, 2010). Recording and assessable productivity of a broiler breeder is relatively long term and expensive. Simulation modeling can assist in better understanding of a farming system by estimating the productivity. Modelling integrates knowledge of the components of a farm system with their interactions and can be used to identify differences in efficiency of production by varying inputs and out puts (Olney and Kirk, 1989). Modelling

Department of Genetics and Animal Breeding, Chittagong Veterinary and Animal Sciences University, Khulshi, Chittagong-4202, Bangladesh, E-mail: kkhan1567@yahoo.co.uk

(Received: November 09, 2010) 
Bang. J. Anim. Sci. 2010, 39(1\&2)

assists researcher, policy maker and farmer in making decision to improve sustainability and farm profitability. Various types of models for the egg production of broiler breeder have been found in literature: a simple 3 parametric model (Wood model) for individual weekly egg production; a logistic model, which including the both increasing and decreasing phase (Yang et al., 1989; Grossman and Koops, 2001); and a stochastic simulation model of egg production (Alvarez and Hocking, 2007). The applicability of models on egg production under tropical environment including Bangladesh is limited.

The current study was, therefore, designed (i) for assessing the productive and reproductive performance of Hubbard classic broiler parents and (ii) to model the traits of Hubbard classic broiler parents for their prediction.

\section{Materials and Methods}

This study was conducted in 2009 on 6046 Hubbard classic breeder parent in the Bangladesh Rural Advancement Committee (BRAC) Poultry farm in Chittagong.

\section{Performance and management of Hubbard classic broiler parent}

Data on egg production, body weight, feed intake and hatchability performance along with related information on management such as housing, lighting, feeding and nutrition and vaccination were collected from the record book of BRAC poultry farm from 27 to 61 weeks of ages of the hens by visiting the farm frequently. The statistical analysis of the collected data was done by using PROC GLM of SAS (SAS, 2000).

The Hubbard classic broiler parents were reared in environment control house with appropriate bio-security measures. The eggs were hatched by forced-draft electric incubator and on deep litter (disinfected rice husk) floor were used for brooding and also for breeders. The brooder temperature was maintained in the range of $22-35^{\circ} \mathrm{C}$ for a period of 4 weeks. Lighting schedule: first 2 days 24 hours duration with lighting intensity 60 lux; from day 3 to 17 with a 1 hour deduction keeping the lighting intensity 40 to 5 lux; from day 18 to 21 weeks the duration of lighting was 8 hours with lighting intensity 5 lux then the birds were kept under normal lighting conditions. The standard feeding and nutrition schedule for starter was: energy $2800 \mathrm{kcal} / \mathrm{kg}$, CP 19\%, Lysine $1.10 \%$ and Methionine $0.70 \%$; for grower: energy $2700 \mathrm{kcal} / \mathrm{kg}$, CP $16 \%$, Lysine $0.75 \%$ and Methionine $0.55 \%$; for pre-layer: energy $2750 \mathrm{kcal} / \mathrm{kg}$, CP 17\%, Lysine $0.85 \%$ and Methionine 0.50\%; for breeder: energy 2750 $\mathrm{kcal} / \mathrm{kg}$, CP $16 \%$, Lysine $0.75 \%$ and Methionine $0.60 \%$ and for male in production: energy $2700 \mathrm{kcal} / \mathrm{kg}$, CP $14 \%$, Lysine $0.70 \%$ and Methionine $0.60 \%$, respectively. In addition, all other essential vitamins and minerals were balanced. A skip feeding schedule was also followed in every alternative day. Mainly three types of mating (pan mating, flock mating and artificial insemination) were carried out to maintain the quality of hatching eggs. Other management practices such as debarking, laying hen management, and proper vaccination against the infectious diseases were followed. 


\section{Modeling the performances}

The linear regression equation $(\mathrm{Y}=\mathrm{a}+\mathrm{bx})$, where, $\mathrm{Y}$ is the value of the traits, $\mathrm{x}$ is the ages of hens, and $a$ and $b$ are the parameters that define the shape of the curve) and the quadratic polynomial regression equation $\left(Y=a+b x+c x^{2}\right)$, where, $Y$ is the value of the traits, $x$ is the ages of hens, and a, b and c are parameters that define the shape of the curve) were fitted using PROC MIXED of SAS to estimate their parameters (a, b and c). The goodness-of-fit of predicted values to actual records, and model performance were compared by the fit statistics: coefficient of determination $\left(\mathrm{R}^{2}\right)$ and coefficient of variation (CV). The values of $\mathrm{R}^{2}$ and $\mathrm{CV}$ were obtained by fitting each predicted value for each week from linear regression and quadratic polynomial regression, as a dependent variable with model parameters ( $\mathrm{a}, \mathrm{b}$ and $\mathrm{c}$ ) and weekly production as independent variables with the PROC MIXED procedure of SAS. The predicted egg production for Hubbard Classic parents from the linear regression and quadratic polynomial regression was obtained by including its parameter values in PROC GLM of SAS (SAS, 2000).

The following statistical model was used to obtain the least square means for each parameter, goodness of fit ( $\mathrm{R}^{2}$ and $\left.\mathrm{CV}\right)$ and predicted values of the regression models. The model is given as: $Y_{i j}=\mu+A_{i}+$ eij Where, $Y_{i j}$ is the predicted value of the trait, $\mu$ is the overall mean, $A_{i}$ is the effect of age and $e_{i j}$ is the residual effect, distributed as $N\left(0 \sigma^{2}\right)$. The mean differences were compared using least significant difference (lsd) (Steel et al. 1997) at 5\% level of significance.

\section{Results and Discussion}

\section{Productive and reproductive performance of Hubbard classic broiler parents}

The mean \pm standard error values of different productive and reproductive traits of Hubbard classic broiler parents are shown in Table 1. Table 1 indicates that the Hubbard classic was heavier (3412.48 $\pm 137.773 \mathrm{~g} / \mathrm{hen})$ and higher egg producers (egg no.170.99 \pm 1.012/hen/year in comparison with other broiler parents (e.g. Cobb-500). Enting (2007) found Cobb-500 attained 2550g live weight at 65 weeks of age and the female breeder produce 163.3 eggs (Cobb-500, 2008). In the present study, average feed intake was $167.7 \pm$ $7.61 \mathrm{~g} /$ hen/day which was higher than the reported value of $156 \mathrm{~g} / \mathrm{hen} /$ day for Cobb-500 (Enting, 2007). However, the hatchability (\%) of Hubbard classic parents was higher (94.5\%) in comparison with standard performance (84\%) of Cobb-500 (Cobb 500, 2008). It has been stated that the performance of Hubbard classic broiler parents is higher in comparison with other available broiler parent stock in Bangladesh (Fattah, 2003).

\section{Model parameters of different traits and curve shape}

The values of linear regression and quadratic polynomial regression equation of weekly egg production, live weight and feed intake of Hubbard classic broiler parents are shown in Table 2. Fig. 1 to 6 showed the curve shape of the weekly egg production, live weight and feed intake of Hubbard classic broiler parents after fitting the linear regression and quadratic polynomial regression. The shape of the regression curve differed between linear regression 
Bang. J. Anim. Sci. 2010, 39(1\&2)

and quadratic polynomial regression within the same trait. The steepness and the flatness of the curve varied on the model parametrs ( $a$, b and $c$ ), number of records and also the mathematical function of the model. Similar factors were reported by Pérochon et al. (1996), Vargas et al. (2000); Brown et al. (2001) and Alam et al. (2009). The 2 parametric simple linear regression model does not provide the typical curve shape for different traits. However, typical curve shape for egg production and live weight was observed after fitting the quadratic polynomial regression. Therefore, it can be stated that the 4 or more order polynomial models or other nonlinear or logistic models could provide typical shape of the curve. Miyoshi et al. (1996) showed that nonlinear models provided good shape for egg production.

Table 1. Productive and reproductive performance of Hubbard classic broiler parents

\begin{tabular}{|l|r|}
\hline \multicolumn{1}{|c|}{ Traits } & Mean \pm SE \\
\hline Average weight (g) & $3412 \pm 137.7$ \\
Average feed intake (g/day/bird) & $167.7^{*} \pm 7.61$ \\
Total egg production (no/bird/year) & $171^{*} \pm 1.0$ \\
Egg production (\%) & $69.7 \pm 14.33$ \\
Hatchability (\%) & $94.5 \pm 9.93$ \\
\hline
\end{tabular}

$* \mathrm{P}<0.05$

\section{Actual and predicted yields of different traits}

The actual and predicted mean \pm standard error values of different traits of Hubbard classic broiler parents are shown in Table 1 and 2.

Table 2. Estimated model parameters (a, b and c), fit statistics $\left(R^{2}\right.$ and $C V$ ) and predicted values of different traits of Hubbard classic broiler parents

\begin{tabular}{|c|c|c|c|c|c|c|}
\hline \multirow[t]{2}{*}{ Traits } & \multicolumn{3}{|c|}{ Linear regression } & \multicolumn{3}{|c|}{ Polynomial regression } \\
\hline & $\begin{array}{c}\text { Egg } \\
\text { production }\end{array}$ & Live weight & Feed intake & $\begin{array}{c}\text { Egg } \\
\text { production }\end{array}$ & Live weight & Feed intake \\
\hline Intercept (a) & $4.18^{x} \pm 0.411$ & $\begin{array}{c}3362.11^{\mathrm{x}} \pm \\
70.701\end{array}$ & $\begin{array}{c}171.45 \pm \\
3.145\end{array}$ & $1.15^{\mathrm{y}} \pm 0.619$ & $\begin{array}{c}2584.19^{\mathrm{y}} \pm \\
7.451\end{array}$ & $\begin{array}{c}172.55 \pm \\
2.848\end{array}$ \\
\hline Slope (b) & $0.01^{\mathrm{y}} \pm 0.009$ & $1.24^{y} \pm 1.566$ & $-0.07 \pm 0.069$ & $0.16^{\mathrm{x}} \pm 0.029$ & $\begin{array}{c}38.51^{\mathrm{x}} \pm \\
1.747\end{array}$ & $-0.13 \pm 4.282$ \\
\hline Curve shape (c) & - & - & & $\begin{array}{c}-0.0016 \pm \\
0.0003\end{array}$ & $-0.42 \pm 0.011$ & $\begin{array}{c}0.00059 \pm \\
0.017\end{array}$ \\
\hline $\mathrm{R}^{2}$ & $0.10^{\mathrm{y}} \pm 0.037$ & $0.04 \pm 0.001$ & $0.07 \pm 0.001$ & $0.19^{x} \pm 0.009$ & $0.04 \pm 0.110$ & $0.06 \pm 0.061$ \\
\hline $\mathrm{CV}$ & $\begin{array}{c}25.87^{\mathrm{x}} \pm \\
0.245\end{array}$ & $6.12 \pm 0.123$ & $5.54 \pm 0.165$ & $\begin{array}{c}24.12^{\mathrm{y}} \pm \\
0.365\end{array}$ & $6.11 \pm 0.335$ & $5.51 \pm 0.221$ \\
\hline Predicted & $\begin{array}{l}163.23^{y} \\
\pm 0.099\end{array}$ & $\begin{array}{c}3416.67^{\mathrm{y}} \pm \\
0.218\end{array}$ & $178 \pm 0.135$ & $\begin{array}{c}164.53^{\mathrm{x}} \pm \\
0.033\end{array}$ & $\begin{array}{c}3517.22^{\mathrm{x}} \pm \\
0.715\end{array}$ & $\begin{array}{c}177.69 \pm \\
0.761\end{array}$ \\
\hline
\end{tabular}

Means with different superscripts ( $\mathrm{x}$ and $\mathrm{y}$ ) between models within trait are different at $\mathrm{P}<0.05$ 
Performance and modelling of egg production
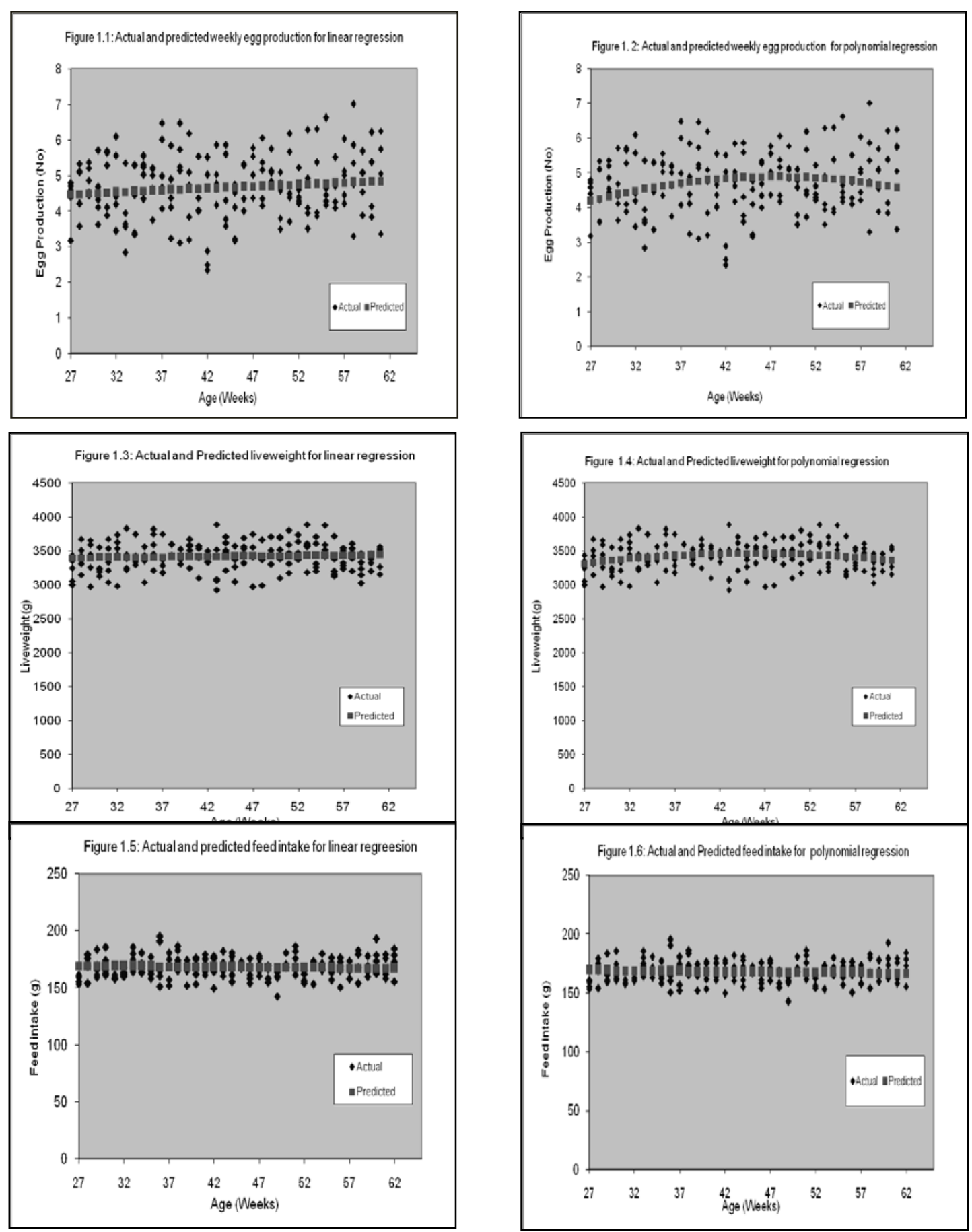

Fig. 1. Curve of the different traits for Hubbard classic broiler parents obtained from linear regression and quadratic polynomial regression 
Bang. J. Anim. Sci. 2010, 39(1\&2)

The total average live weight and feed intake calculated by the BRAC were lower than the values predicted from the regression equations (Table 1 and 2) but they calculated higher egg production than the predicted yield. The lower $\mathrm{R}^{2}$ and $\mathrm{CV}$ value of live weight and feed intake indicated the differences between models and also between actual and predicted value. The higher $\mathrm{R}^{2}$ and CV values indicated a good fit between models and also between actual and predicted values (Alam et al., 2009).

This finding differed with the results obtained by Alvarez and Hocking (2007). Who reported that the actual and predicted egg production was similar with higher $\mathrm{R}^{2}$ value (0.93-90.98). The primary reasons for the lower values in this study might be due to the fact that there was no attempt to account for the shape of production and also about the growth curve and there was no adjustment to length of production. The length of egg production has the positive effects on total egg production agreed well with McAinsh and Kristensen (2004) and Johnston and Gous, (2006). Besides, the predicted yield also differed with the predicted ability of the model parameters, model functions. Similar factors were also reported by Vargas et al. (2000); Brown et al. (2001) and Alam et al. (2009).

\section{Conclusion}

The Hubbard classic broiler parent has appeared to be a good performer under Bangladesh condition. The total average live weight and feed intake calculated to be lower but BRAC report showed higher egg production than the predicted values as they failed to account for the shape of egg production and growth curve. Therefore, for calculating the actual egg production all the factors should be considered. This study might be helpful in reducing the costing for record keeping through an estimate on the total number of egg produced. Further study is needed with 4 or more order polynomials and other non-linear and logistic models for the estimation of predicted total yields. This study will also assist researchers and business personnel's in decision making on rearing any broiler parents.

\section{Acknowledgements}

The authors express their sense of gratitude to the authority of Chittagong Veterinary and Animal Sciences University for their support and encouragements for this study. The authors are also grateful to the BRAC authority for their cordial cooperation.

\section{Literature Cited}

Alam, M. R., Khan, M. K. I. and Khanom, J. 2009. Prediction of lactation milk yield from test day records using wood model. Wayamba Journal of Animal Sciences, Date: 2009-10-17 Number: 1255776225. http://www.wayambajournal.com/papers/1255776225.php

Alvarez, R. and Hocking, P. M. 2007. Stochastic model of egg production in broiler breeders. Poult. Sci., 86: 1445-1452. 


\section{Performance and modelling of egg production}

Asghar, A., Farooq, M. Mian, M. N. and Khurshid, A. 2000. Economics of broiler production in Mardan division . J. Rural Develop. Administ., 32: 56-64.

Brown, M. A., Brown, Jr. A. H., Jackson, W. G. and Miesner, J. R. 2001. Genotype $\times$ environment interactions in milk yield and quality in Angus, Brahman and reciprocal cross cows on different forage systems. J. Anim. Sci., 79: 1643-1649.

Cobb-500, 2008. Breeder management supplement. http:/www.cobb-vantress.com/contactus/ brochures/cobb500FF_Breeder_Mngmt_Supp_2008.pdf.

Enting, H. 2007. Effect of low density feeds on performance of broiler breeders and their offspring. Proceedings of the $17^{\text {th }}$ Australian Poultry Science Symposium,” New South Wales, Australia. http://www.zootechnicainternational.com/article-archive/nutrition/677

Farooq, M., Mian, M. A., Faisal, S., Durrani, F. R., Arshad, M. and Khurshid, A. 2001. Status of broiler breeder stocks in Abbotabad and Mansehera. Sarhad J. Ag., 17: 489-495.

Farooq, M., Haq, Z. U., Mian, M. A., Durani, F. R. and Sayed, M. 2003. Cost of production, gross return and net profit in commercial egg production. Pakistan Vet. J., 23: 41-48.

Fattah, K. A. 2003. Poverty alleviation and Poultry development strategies in Bangladesh. Proceeding of the First Annual Scientific Conference, Feb. 22-24, CGVC, University of Chittagong, pp: 192-200.

Grossman, M. and Koops, W. J. 2001. A model for individual egg production in chickens. Poult. Sci., 80(7): 859-867.

Hossain, M. E., Chowdhury, S. D., Ahammed, M., Pramanik, M. A. H. and Rahman, M. R. 2005. Growth performance of kasila broiler parent stock reared on quantitative feed restriction, under Bangladesh condition. Intl. J. Poult. Sci., 4: 153-158.

Hubbard, 2010. A manual on Hubbard classic. www.hubbardbreeders.com/products.php?id=7

Johnston, S. A. and Gous, R. M. 2006. Modelling Egg Production in Laying Hens. In: Mechanistic Modelling in Pig and Poultry Production, Gous, R. M., T. R. Morris and C. Fisher (Eds.). CABI, Wallingford, UK. pp. 229- 259.

McAinsh, C.V. and Kristensen, A.R. 2004. Dynamic modelling of a traditional African chicken production system. Tropical Anim. Health and Prod., 36: 609-626.

Miyoshi, S., Luc, K. M., Kuchida, K. and Mitsumoto, T. 1996. Application of non-linear models to egg production curves in chickens. Japanese J. Poult. Sci., 33: 178-184.

Olney, G. R. and Kirk, J. 1989. A mangement model that helps increase profit on Western Australian dairy farms. Agril. Syst., 31: 367-380.

Pérochon, L., Coulon, J. B. and Lescourreet, F. 1996. Modelling lactation curves of dairy cows with emphasis on individual variability. Anim. Prod., 63: 189-200.

Saleque, M. A. and Rozen, S. M. 2007. Seasonal effects on the performance of broilers in Bangladesh. In: Proceedings of the $5^{\text {th }}$ International Poultry Show and Seminar, The World Poultry Science Association, March 1-3, 2007, Dhaka, Bangladesh, pp: 10-17.

SAS $^{\circledR}$, User’s Guide. Statistics. ${ }^{\text {th }}$ edn. Cary (NC): SAS Institute Inc., 2000.

Steel, R. G. D., Torrie, J. H., Dickey, D. A. 1997. Principles and procedure of statistics- A Biometrical Approach. $3^{\text {rd }}$ ed. Mc Graw-Hill Co., Inc., New York and London, pp: 139-177.

Vargas, B., Koops, W. J., Herrero, M. and Van, Arendonk, A. J. 2000. Modelling extended lactations of dairy cows. J. Dairy Sci., 83: 1371-1380.

Yang, N. and Wu, C. and McMillan, I. 1989. New mathematical model of poultry egg production. Poult. Sci., 68: 176-181. 